This document was prepared in conjunction with work accomplished under Contract No. DEAC09-96SR18500 with the U.S. Department of Energy.

\title{
DISCLAIMER
}

This report was prepared as an account of work sponsored by an agency of the United States Government. Neither the United States Government nor any agency thereof, nor any of their employees, makes any warranty, express or implied, or assumes any legal liability or responsibility for the accuracy, completeness, or usefulness of any information, apparatus, product or process disclosed, or represents that its use would not infringe privately owned rights. Reference herein to any specific commercial product, process or service by trade name, trademark, manufacturer, or otherwise does not necessarily constitute or imply its endorsement, recommendation, or favoring by the United States Government or any agency thereof. The views and opinions of authors expressed herein do not necessarily state or reflect those of the United States Government or any agency thereof.

This report has been reproduced directly from the best available copy.

Available for sale to the public, in paper, from: U.S. Department of Commerce, National Technical Information Service, 5285 Port Royal Road, Springfield, VA 22161

phone: (800) 553-6847

fax: (703) 605-6900

email: orders@ntis.fedworld.gov

online ordering: http://www.ntis.gov/support/index.html

Available electronically at http://www.osti.gov/bridge

Available for a processing fee to U.S. Department of Energy and its contractors, in paper, from: U.S. Department of Energy, Office of Scientific and Technical Information, P.O. Box 62, Oak Ridge, TN 37831-0062

phone: (865)576-8401

fax: (865)576-5728

email: reports@adonis.osti.gov 


\section{FRACTURE TOUGHNESS PROPERTIES OF SAVANNAH RIVER SITE STORAGE TANK ASTM A285 LOW CARBON STEEL}

\author{
K. H. Subramanian \\ Savannah River Technology \\ Center \\ Westinghouse Savannah \\ River Company \\ Aiken, SC USA
}

\author{
A. J. Duncan \\ Savannah River Technology \\ Center \\ Westinghouse Savannah \\ River Company \\ Aiken, SC USA
}

\author{
R. L. Sindelar \\ Savannah River Technology \\ Center \\ Westinghouse Savannah \\ River Company \\ Aiken, SC USA
}

\begin{abstract}
A materials test program was developed to measure mechanical properties of ASTM A285 Grade B low carbon steel for application to structural and flaw stability analysis of storage tanks at the Department of Energy (DOE) Savannah River Site (SRS). Under this plan, fracture toughness and tensile testing are being performed at conditions that are representative of storage tank conditions on steels that span compositions within ASTM A285 specifications. The testing is being done within the framework of a statistical test matrix and the data collected will be used to develop a predictive model for materials properties. The results presented herein are limited to a subset of data comparing for comparison of a recent vintage steel versus an older steel for fracture resistance behavior. These preliminary results indicate that dynamic loading rates result in a greater increase in the fracture toughness response in the case of the recent vintage steels of lower carbon content when compared to the archival heat of high carbon content. In addition, ductile tearing in the archival, high carbon steel was more likely to be interrupted by cleavage fracture at lower fracture energies than the modern, low carbon steel.
\end{abstract}

\section{INTRODUCTION}

A structural integrity program is in place to ensure structural adequacy of storage tanks built during the 1950's and 1960's at the DOE-SRS. As part of the structural integrity program, fracture mechanics analysis will be done to ensure the flaw tolerance of the tanks. Fracture mechanics analysis can be used to determine the critical crack size that can lead to unstable ductile tearing conditions.

The validity and limitations of the fracture mechanics analysis depend, in part, upon the available mechanical property data applicable to the material of construction. The earliest storage tanks built at the SRS were made of American Society for Testing Materials (ASTM) A285, Grade B steel. The nominal compositions are shown in Table 1 . The steel suppliers provided tensile properties, but impact properties were measured for only one sample of tank steel. As a result, a mechanical testing program was developed to provide input to a model that can calculate a statistically based estimate of material properties for flaw specific structural analysis. Fracture toughness testing and tensile testing are being performed on ASTM Type A285 steels at conditions reflective of operational conditions.

Materials were selected to closely match the materials used in storage tanks used at Savannah River Site. Twelve total heats were chosen for 
inclusion in the test matrix.[1] In addition to the commercially obtained heats, one flange of archival steel found at the Savannah River Site (designated as heat "Adisk") was used to complete the test matrix. On-site compositional analysis has shown that the chemical composition of the heat is outside of the bounds of ASTM A285 Grade B steel but within the bounds of Grade C. However, the mechanical properties determined from the testing of the steel may reveal some inherent properties of steel processed in that era.

Table 1: ASTM Specification for A285-50T Grade B and A-285-90 Grade C.

\begin{tabular}{|c|c|c|}
\cline { 2 - 3 } \multicolumn{1}{c|}{} & \multicolumn{2}{c|}{ Composition (Max wt. \%) } \\
\cline { 2 - 3 } & $\begin{array}{c}\text { Grade B } \\
\underline{(\mathbf{1 9 5 0 )}}\end{array}$ & $\begin{array}{c}\underline{\text { Grade C }} \\
\underline{\underline{\mathbf{1 9 9 0}}}\end{array}$ \\
\hline \hline Carbon & 0.2 & 0.29 \\
\hline Manganese & 0.8 & 0.9 \\
\hline Phosphorus & 0.035 & 0.35 \\
\hline Sulfur & 0.04 & 0.35 \\
\hline
\end{tabular}

TEST MATRIX

The fracture toughness of A285 steel is highly dependent on material specifications and loading conditions. Variables relevant to the material and load conditions for storage tanks were defined (as shown in Table 2) and a statistical test matrix was designed for fracture toughness testing.

Mechanical testing is in progress as per the statistically designed test matrix, and a predictive model derived from the composite data set will be used as input properties for flaw stability analysis. The effect of (1) chemical composition, (2) microstructure, (3) temperature, (4) orientation, and (5) loading rate are being investigated. The full data set that will be ultimately compiled in the testing program will allow the construction of analytical models to predict fracture properties as a function of composition and operational conditions.

The specified model is quadratic and includes linear terms for continuous variables of carbon, manganese, sulfur, and temperature, and first order terms for the discrete variable of loading rate and orientation. Tolerance and confidence bands can be developed at the desired confidence levels for the desired material and test conditions to develop properties input for flaw stability analyses.
Table 2: Test Matrix Variable Description

\begin{tabular}{|c|c|c|c|}
\hline Variable & $\underline{\text { Type }}$ & \multicolumn{2}{|c|}{ Span } \\
\hline Temp & Cont. & $60^{\circ} \mathrm{F}$ & $80^{\circ} \mathrm{F}$ \\
\hline C Content & Cont. & $0.08 \mathrm{wt} \%$ & $0.29 \mathrm{wt} \%$ \\
\hline Mn Content & Cont. & $0.35 \mathrm{wt} \%$ & $0.9 \mathrm{wt} \%$ \\
\hline S Content & Cont. & $0.005 \mathrm{wt} \%$ & $0.04 \mathrm{wt} \%$ \\
\hline Strain Rate & Disc. & $\begin{array}{c}\text { Quasi- } \\
\text { Static }\end{array}$ & Dynamic. \\
\hline Orientation & Disc. & L-T & T-L \\
\hline
\end{tabular}

\section{MATERIALS}

Recent fracture toughness testing has focussed on determining the variances in the mechanical properties of the archival steel when compared to current vintage steel. The results of recent fracture toughness testing from the Adisk heat and P134 heat are presented herein. The chemical composition and tensile properties as given by the vendor for heat P134, and as tested for the Adisk are shown in Table 3. It is seen that the carbon content of the Adisk heat is much greater than the $\mathrm{P} 134$ heat, and is expected to have the greatest effect on toughness.

Table 3: Materials Tested including Tensile Properties, Chemical Composition, and Plate Thickness.

\begin{tabular}{|c|c|c|c|c|c|c|}
\hline Heat & $\frac{\text { Thickness }}{\text { (in.) }}$ & $\underline{\mathrm{C}}$ & $\underline{\text { Mn }}$ & $\underline{\mathbf{S}}$ & $\begin{array}{l}\underline{\sigma}_{\text {UIS }} \\
\underline{(\mathbf{k s i})}\end{array}$ & $\begin{array}{c}\underline{\sigma}_{\mathrm{Y}(0.2 \%)} \\
\underline{(\mathrm{ksi})}\end{array}$ \\
\hline P134 & 1.125 & 0.083 & \begin{tabular}{|l|l|}
0.854 \\
\end{tabular} & 0.032 & 60 & 40 \\
\hline Adisk & 1.125 & 0.23 & \begin{tabular}{|l|l|}
0.42 \\
\end{tabular} & 0.027 & 65 & 34 \\
\hline
\end{tabular}

Post-test characterization and comparisons of fracture surface phenomena were made in order to possibly determine microstructural features that may lead to the variances.

\section{TESTING}

The conditions and heats selected for fracture toughness testing (as part of the complete test matrix) are presented in Table 4. Fracture toughness testing concentrated primarily on effects of loading rate, thickness, and chemical composition. A total of 17 fracture toughness tests, in the form of J-R curve testing, are presented herein. Nine fracture toughness tests performed on each of the heats are presented. The complete test matrix consists of 108 tests. The results shown include results from 7 fracture 
toughness tests previously presented. These are included for comparison purposes.

Table 4: Fracture Toughness Test Matrix as part of Complete Test Design

\begin{tabular}{|c|c|c|c|c|}
\hline$\underline{\mathbf{S}}$ & $\begin{array}{l}\text { Thick. } \\
\text { (in.) }\end{array}$ & $\underline{\mathbf{L}}$ & $\begin{array}{c}\mathbf{T} \\
(\stackrel{\circ}{\mathbf{F}}) \\
\end{array}$ & $\underline{\mathbf{0}}$ \\
\hline P134-1* & $\overline{0.85}$ & atic & 80 & T-L \\
\hline P134-2* & 85 & & 80 & \\
\hline P134-3* & 875 & & 60 & \\
\hline P134-4 & 475 & & 60 & L- \\
\hline$P 134-5$ & 475 & & 60 & L-T \\
\hline P134-6 & 475 & & 60 & L-T \\
\hline P134-7 & 75 & & 60 & L-T \\
\hline$P 134-8$ & 475 & C & 80 & L-T \\
\hline$P 134-9$ & 75 & & 80 & L-T \\
\hline ADisk-1* & 875 & & 60 & T-L \\
\hline ADisk-2* & 0.875 & Que & 60 & T-L \\
\hline ADisk-3* & 0.875 & & 80 & T-L \\
\hline ADisk-4* & 75 & & 80 & T-L \\
\hline Adisk-5 & 0.475 & Quasi-Static & 60 & L-T \\
\hline Adisk-6 & 75 & $\cdot \mathrm{C}_{1} \cdot \mathrm{C}^{\prime}$ & 60 & L-T \\
\hline Adisk-7 & 475 & tatic & 80 & L-T \\
\hline$s k-8$ & 75 & & 80 & L-T \\
\hline Adisk-9 & 475 & Quasi-Static & 60 & $1-$ \\
\hline
\end{tabular}

* These were are presented in Reference 1.

The standard method for J-integral characterization described in ASTM Standard E1820: "Standard Test Method for Measurement of Fracture Toughness" was followed for fracture toughness testing and development of J- $\Delta \mathrm{a}$ curves.[2] Fracture toughness tests were conducted on compact tension specimens machined and fatigue pre-cracked to ASTM E1820 specifications. The specimens were $20 \%$ sidegrooved to prevent extensive crack tunneling.

The quasi-static and dynamic loading rates (load-line displacement rates) were $1.24 \times 10^{4} \mathrm{in} / \mathrm{sec}$ and 0.11 $\mathrm{in} / \mathrm{sec}$ respectively. Dynamic loading rates were calculated using a bounding loading rate calculated to represent seismic conditions. The loading rate used was specific for the specimen geometry. Test temperatures were maintained between 60 and $80^{\circ} \mathrm{F}$.

Previous testing indicated that the narrow temperature range has negligible effects on fracture toughness. Considering the narrow range of temperatures selected for testing in the present program, this implies that the present test temperatures fall above the ductile-to-brittle transition temperature (DBTT) of the steel heats. A dramatic test temperature effect would be evident in the fracture properties if the test temperatures fell within the transition range.

In previous testing, A285 Grade B specimens were observed to exhibit $15 \mathrm{ft}-\mathrm{lb}$. transition temperatures in a range of 20 to $45^{\circ} \mathrm{F}$. This correlates to a fracture transition region spanning from 20 to $100^{\circ} \mathrm{F}$. The upper transition and upper shelf regions are observed to extend from approximately 70 to $100^{\circ} \mathrm{F}$.[3] Additionally, a statistical review of the nil-ductility transition (NDTT), shows that $99 \%$ of the A285C steel should have a NDTT below $70^{\circ} \mathrm{F}$.[4]

\section{Compact Tension Test}

Fracture toughness testing was done on an MTS ${ }^{\mathrm{TM}}$ hydraulic load frame in a temperature controlled test chamber (shown in Figure 1). Temperature was measured/monitored using a calibrated temperature probe and the test chamber controller thermocouple during testing. Load, load-line displacement and crack lengths were measured for calculation of J- $\Delta \mathrm{a}$ curves. A crack-opening displacement (COD) gage was used to measure displacement up to 0.5 inches. Load-line displacement was measured through the MTS controller at greater crack openings to allow for extensive crack opening during testing. It has been found that extensive ductile crack growth allowed for greater crack opening.

Crack lengths were measured using the Direct Current Potential Drop Method (DCPD). The specimen was instrumented as described in ASTM E647-95a, "Standard Test Method for Measurement of Fatigue Crack Growth Rates."[5] Dynamic fracture testing (rapid-load testing) covered intermediate loading rates between quasi-static and impact Charpy tests. The DCPD results were calibrated with post-test optical crack length measurements of the fatigue pre-crack and total crack length after testing. 


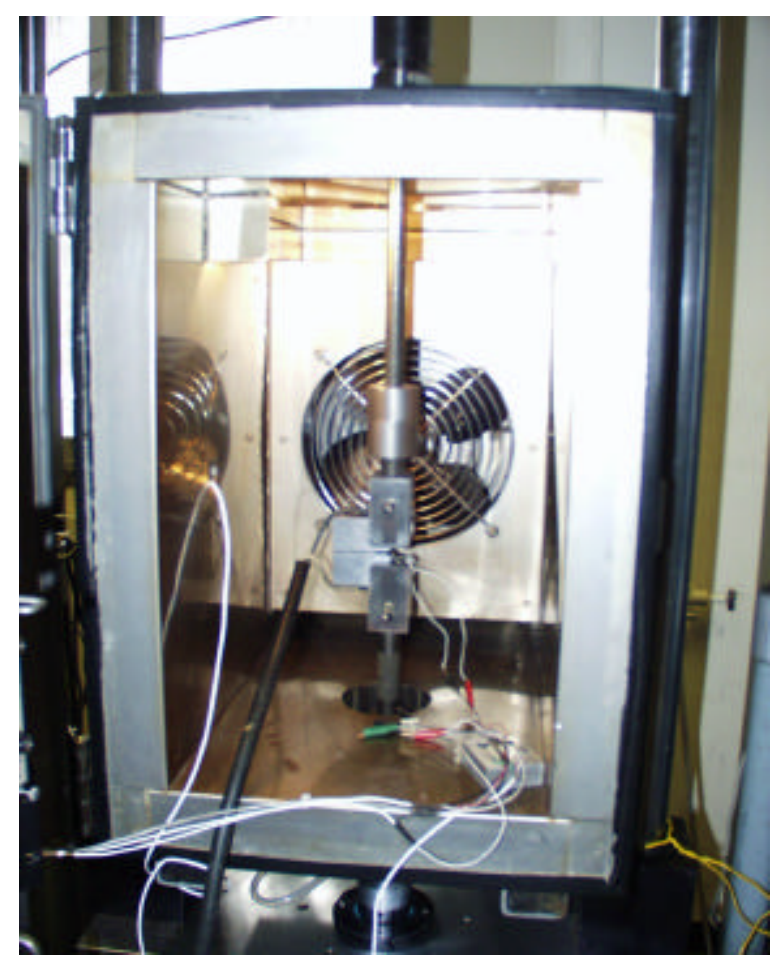

Figure 1: Specimen Setup in Test Chamber with Crack Length Potential Drop Measurement System

\section{RESULTS/DISCUSSION}

Fracture toughness curves for each of the compact tensions tests performed were compiled in the form of J-R curves. Figures 2-5 show the J-R curve behavior of the Adisk and P134 heats. The data include specimens of two different section thicknesses and orientations. Fracture toughness test results performed at the dynamic and quasi-static rates are presented. The first observation that can be noted is that temperature has a minimal effect on properties within the range tested.

The effect of loading rate on J-R curve behavior is complicated. Results suggest that tests performed at temperatures above the ductile to brittle transition region lead to increased fracture resistance energy with loading rate. This result is to be expected when considering that the strain hardening rate increases with increasing loading rate. Such behavior translates a higher resistance to tearing, and hence, a higher J-R curve for high loading rates. This trend is exhibited in the P134 heat. In Figures 2 and 3, dynamic loading rates increase the J-R curve compared to similar tests conducted at static loading rates. However, Adisk does not exhibit the same behavior. Specifically in Figures 4 and 5, the test conducted at higher loading rates do not exhibit substantially higher J-R curves. However, the effect of increasing carbon content is to potentially become the controlling variable in fracture toughness response. When considering both heats in Figure 6, in appears that the range of fracture energy exhibited increases with decreasing carbon content.

In Figures 3 and 5, the J-R curves for thicker samples are presented. As is evident, the increased loading rate increases the J-R curve in the P134 heat while it slightly reduces the J-R curve for the Adisk heat. In the thinner sections (see Figure 2 and 4), the fracture energy increases with loading rate in both cases (although not significantly in the case of Adisk). In the case of sample AD-5, the fracture resistance grew rapidly initially and led to the premature intervention of cleavage fracture similar to the fracture toughness response of samples tested at the dynamic loading rate.

In Figure 7, the range of the fracture energy variation exhibited increases with decreasing section thickness. This range in variability may be related to the presence of defects toward the center of the plate. In Figures 8 and 9, optical micrographs of each heat of steel are shown in the orientation perpendicular to the rolling direction. The presence of defects along the centerline of the plate can be noted in both heats (denoted by short arrows). These defects appear to be regions of high inclusion (i.e., MnS) content which are distributed in bands during rolling (see Figure 10). When samples of reduced section thickness are machined from these plates the presence of these defects reduces the fracture properties to a greater extent than the thicker samples. The result is an abnormally low J-R curve when compared to the thicker specimens. Since the distribution of these defects is related to the overall segregation in the ingot microstructure, a wide variance is expected from sample to sample.

Although, modern steels (e.g., P134) are generally lower in oxygen, sulfur and phosphorus contents, they are not free of these species and the resulting segregation that they produce. Sulfur and phosphorus tend to segregate to a greater extent than other elements. As a result, manganese sulfide $(\mathrm{MnS})$ inclusions have been found to line up along the center of the hot rolled plate. The tendency of elements to segregate during solidification increased with the time required for solidification. Killed steels generally exhibit the least amount of segregation and rimmed steels the most. The processing history of the Adisk heat is unknown, but all plate steel used to construct the storage tanks are known to be semikilled. In accordance with steelmaking practices of 
that era, it is expected that silicon and/or aluminum were used as the killing agent.

Figures 8-10 illustrate the presence of non-metallic inclusions in both archival and modern steels. This leads to detrimental properties in certain orientations. In the case of P134 the high sulfur content creates enough MnS inclusions to be seen optically. The higher pearlite volume fraction of the ADISK heat obscures the $\mathrm{MnS}$ inclusions even thought sulfur content is similar to that of Heat P134. Regardless of their presence, however, the impact of processing differences in the case of these two heats is overshadowed by the potent effect of carbon on properties (see Figure 6).

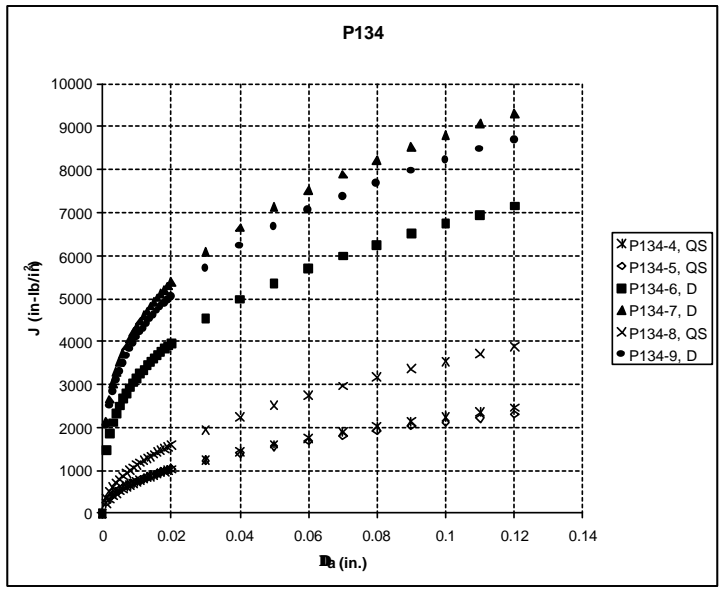

Figure 2: J-R Fracture Toughness Curves for Recent Fracture Toughness Testing of Heat P134 ( $\mathrm{t}=0.475$ ").

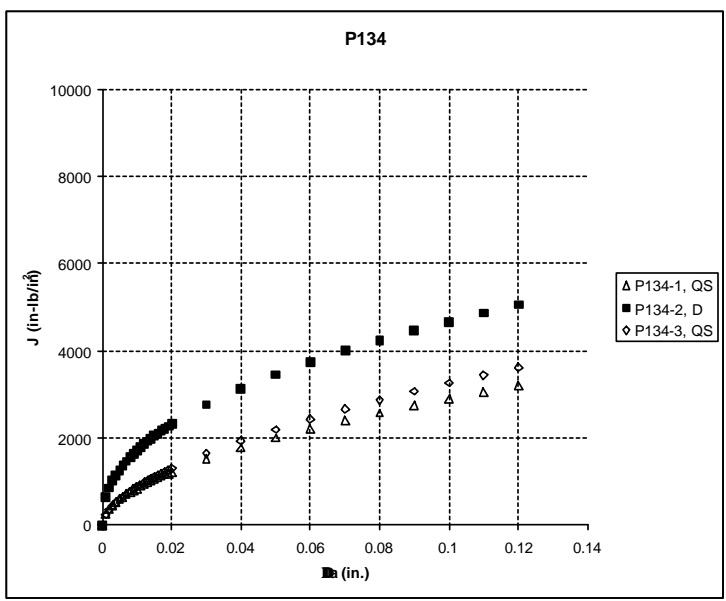

Figure 3: J-R Fracture Toughness Curves for Heat P134 from Reference $1(0.85<\mathrm{t}<0.875$ ”).

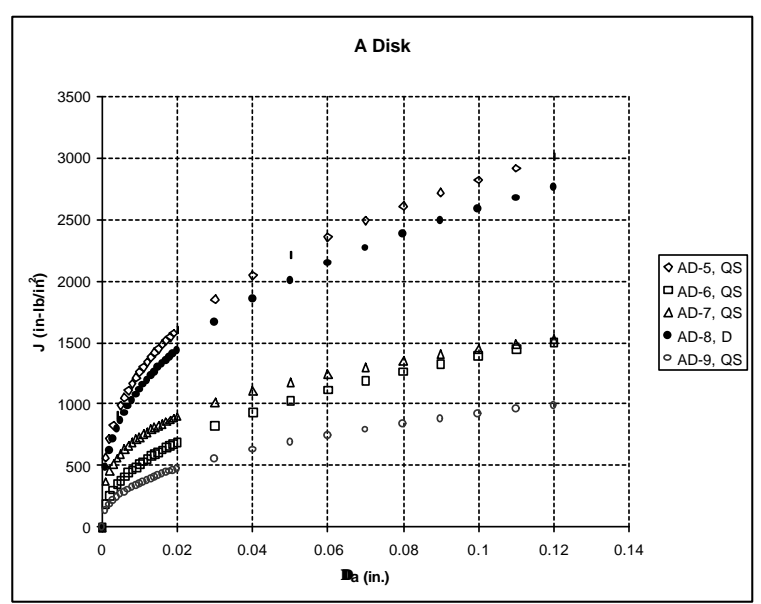

Figure 4: J-R Fracture Toughness Curves for Recent Fracture Toughness Testing for Heat Adisk $(\mathrm{t}=0.475$ in. $)$.

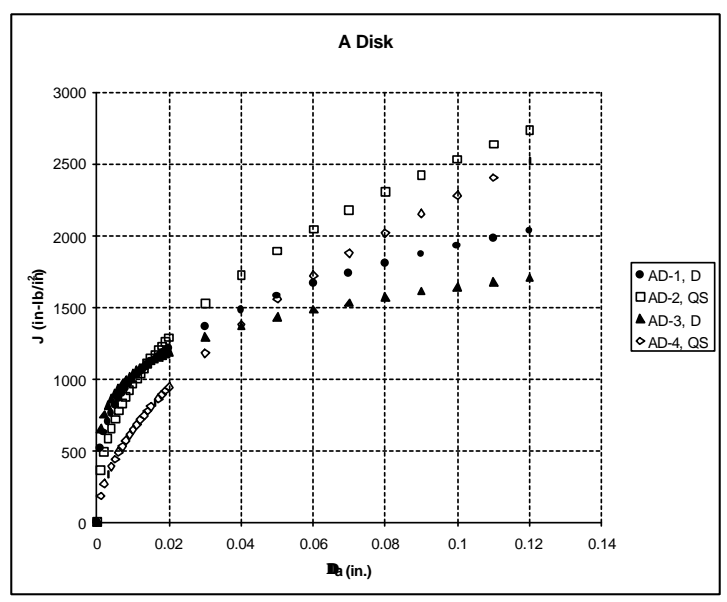

Figure 5: J-R Fracture Toughness Curves for Heat ADisk, from Reference 1. $(\mathrm{t}=0.875 \mathrm{in}$.). 


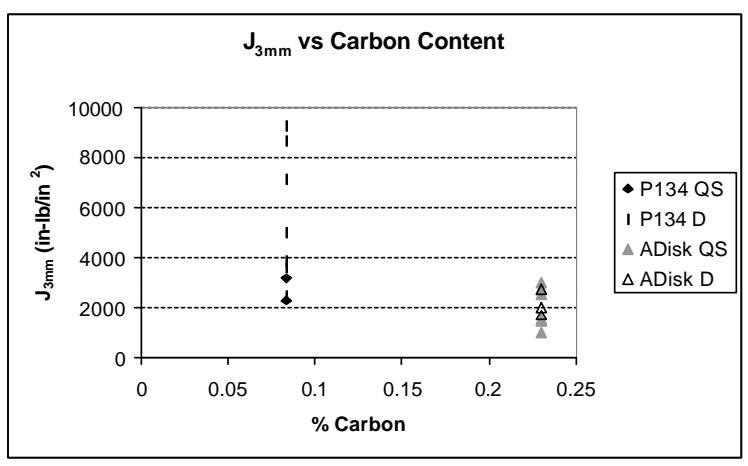

Figure 6: Fracture Energy at 3mm Crack Growth as a Function of Carbon Content

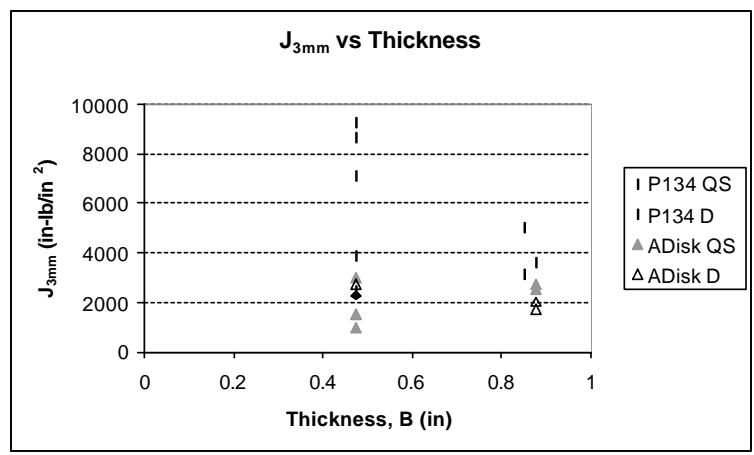

Figure 7: Fracture Energy at 3mm Crack Growth as a Function of Thickness

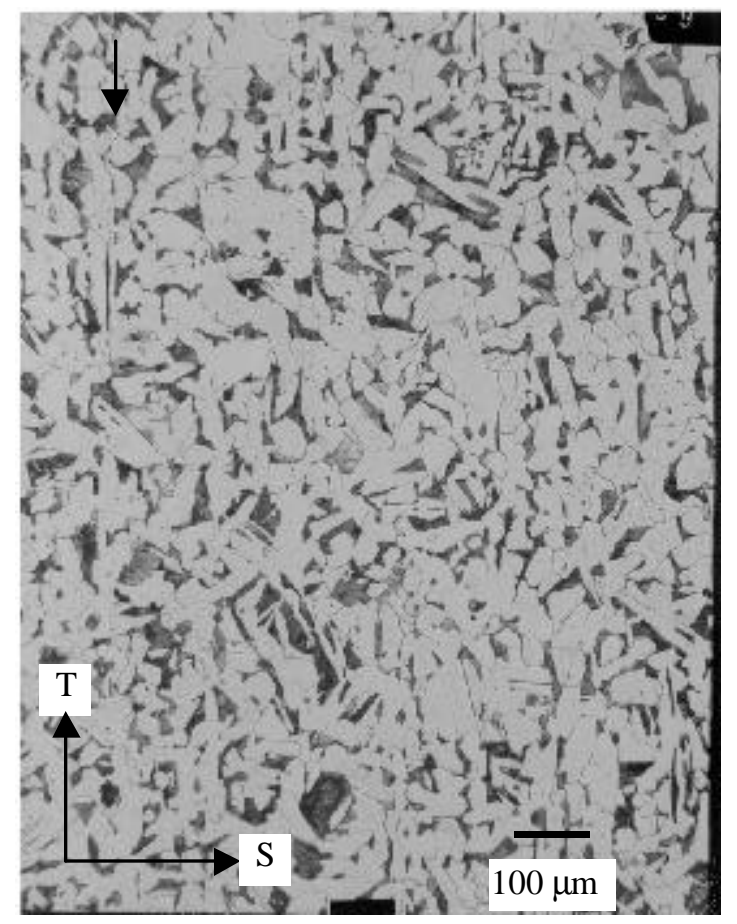

Figure 8: Microstructure of the Adisk heat.

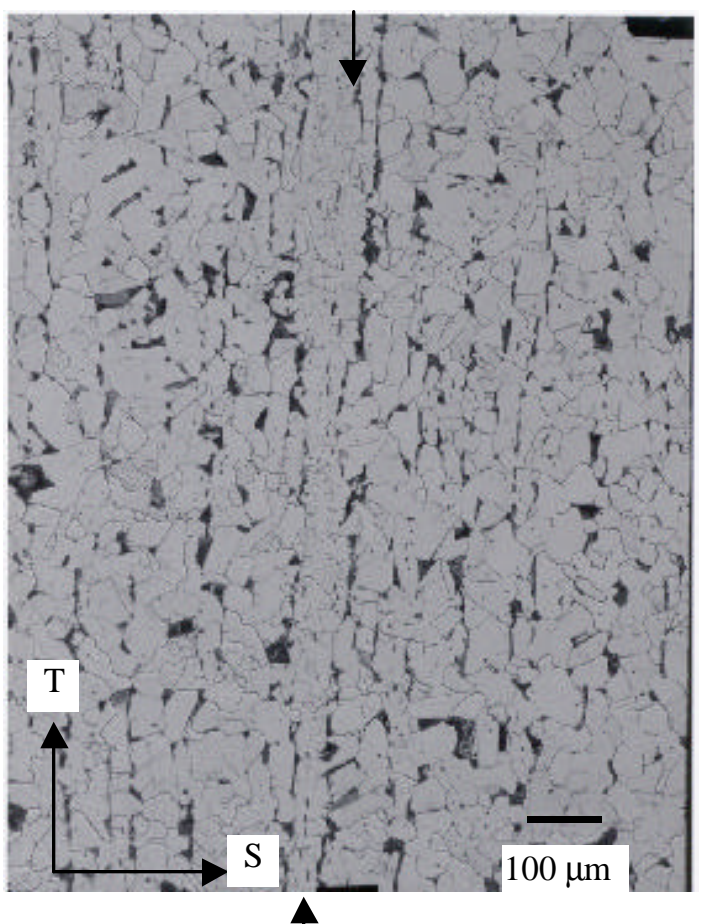

Figure 9: Micrograph of the P134 Heat of Steel

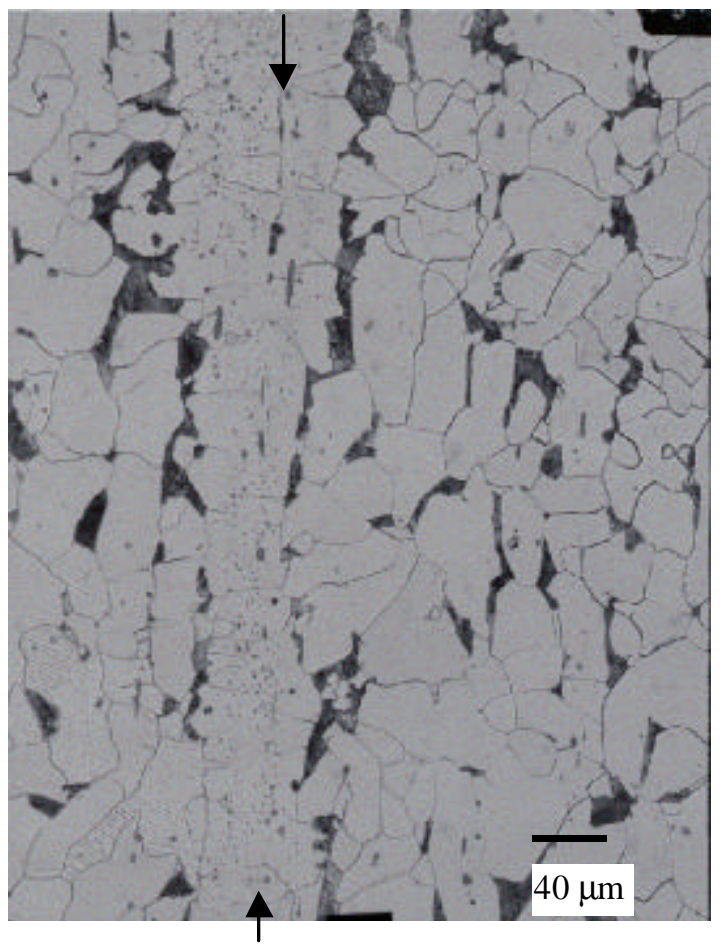

Figure 10: Higher Magnification Micrograph of the P134 Heat of Steel Showing the presence of inclusions.

\section{CONCLUSIONS}

The current results have permitted an initial evaluation of the effects of different variables on the 
fracture energy. It is shown that changes in test temperature in the ranges tested have minimal effects. The preliminary findings reveal that higher loading rates lead to more rapidly increasing J-curves in recent vintage low-carbon steels in comparison with quasi-static loading rates. However, for archival material, containing higher carbon contents, the effect is less pronounced. The onset of cleavage fracture after extended ductile tearing is also seen as a function of loading rate, as tests conducted on archival material isolated loading rate as a variable. The failure mechanism in these cases revealed the competition between ductile tearing and cleavage failure. The observation of cleavage onset after ductile tearing was seen to be higher at higher loading rates. The present tests highlight the continuing need to determine the allowable crack growth resistance as well as to quantify the ductile tearing to cleavage fracture transition.

\section{PATH FORWARD}

Additional fracture toughness tests will be performed to complete the test matrix. Results from the complete data set will be used to determine the sensitivity of the predictive model to each matrix variable. Microstructural analysis will be conducted to develop a fundamental understanding of the role of microstructure on fracture energy and to determine more quantitative structure/property relationships. Finally, a phased approach to large-scale tests on actual tank materials will validate the application of the predictive property model.

\section{ACKNOWLEDGMENTS}

This work was funded by the U. S. Department of Energy under contract No. DE-AC09-96SR18500. The authors thank Prof. J.J. Lewendowski and Chris J. Tuma of Case Western Reserve University for performing the testing.

\section{REFERENCES}

1 Subramanian, K. H., Duncan, A. J., Sindelar, R. L., Lewandowski, J. J., Tuma, C. J., "Fracture Toughness of ASTM A285 Steel for Fracture Analysis of Savannah River Site Storage Tanks," ASME PVP 2001, Vol. 423, p. 127, July 2001.

2 "Standard Test Method for Measurement of Fracture Toughness," American Society for Testing Materials Annual Book of Standards. Vol. 3.01 Standard E1820, 1999.

3 Menke, B. J., Loss, F. J., Hawthorne, J. R., "Savannah River Nuclear Facility Piping Material
Characterization," prepared for E. I. duPont de Nemours and Co., November 1983.

4 Hamel, F. B., "An Investigation of the Impact Properties of Vessel Steels (A Progress Report)," Process Division of American Petroleum Institute, Vol. 38, No. 3, 1958.

5 "Standard Test Method for Measurement of Fatigue Crack Growth Rates," American Society for Testing Materials Annual Book of Standards. Vol. 3.01 Standard E647, 1999. 